\title{
Avaliação da qualidade da água para irrigação na região Centro Sul no Estado do Ceará
}

\author{
Andréia de A. F. Barroso ${ }^{1}$, Germano E. Gomes ${ }^{1}$, Adriano E. de 0. Lima ${ }^{1}$, \\ Helba A. de Q. Palácioº \& Cleene A. de Lima ${ }^{1}$
}

\begin{abstract}
RESUMO
O semiárido nordestino é caracterizado por ser uma região de altas temperaturas e chuvas irregulares durante 0 ano, em que a deficiência de recursos hídricos é o principal fator limitante da produção agrícola. Este trabalho teve como objetivo avaliar a qualidade das águas superficiais e subterrâneas para irrigação na região Centro Sul, Ceará. As amostras de água foram realizadas em 23 pontos distintos, sendo oito representativos de áquas superficiais e quinze de áquas subterrâneas, compreendendo as cidades de Jucás, Cariús e Q uixelô. O período de coleta ocorreu de abril a junho de 2010 e as análises foram efetuadas no Laboratório de Solos, Águas e Tecidos Vegetais do IFCE Campus Iguatu. O s parâmetros investigados foram: cálcio, magnésio, sódio, potássio, cloreto, carbonato, bicarbonato, sulfato, condutividade elétrica e a relação de adsorção de sódio. U tilizou-se o software Qualigraf, através do diagrama de Piper, para comparar e classificar distintos grupos de água relativamente aos íons dominantes. Os resultados mostraram que as fontes subterrâneas apresentaram maior risco de salinidade e sodicidade quanto ao uso na irrigação e, de acordo com o Diagrama de Piper, predominaram as águas sódicas com $87,0 \%$, quando se consideram os cátions e as cloretadas com $78,3 \%$ quanto aos ânions.
\end{abstract}

Palavras-chave: salinidade, composição iônica, diagrama de Piper

\section{Evaluation of water quality for irrigation in South Central region in the State of Ceará}

\begin{abstract}
The semiarid region is characterized as a region of high temperatures and as well as high temporal and spatial variability of rainfall. The deficiency of water resources is the main limiting factor in agricultural production. This study aimed to evaluate the quality of surface and groundwater for irrigation in South Central, Ceará, Brazil. W ater samples w ere taken at 23 different points, eight representative of surface and underground waters and fifteen from the cities of Jucás, Cariús and Q uixelô. The collection period was from A pril to June 2010 and analysis were performed at the Laboratory of Soil, Water and Plant Tissue of IFCE I guatu Campus. The parameters investigated w ere: calcium, magnesium, sodium, potassium, chloride, carbonate, bicarbonate, sulphate, electrical conductivity and sodium adsorption ratio. The software Q ualigraf was used to perform the classification of samples through the Piper diagram to compare and classify different groups of waters in relation to the dominant ions. The results showed that the sources had higher risk of groundwater salinity and sodicity for use in irrigation and according to the Piper diagram sodic waters prevailed with $87.0 \%$ when considering the cations and the $78.3 \%$ as choride when anions were considered.
\end{abstract}

Key word: salinity, ionic composition, diagram of Piper

\footnotetext{
Trabalho submetido e selecionado no primeiro Simpósio Brasileiro de Salinidade realizado de 12-15/10/2010 em Fortaleza, Ceará, Brasil ${ }^{1}$ IFCE Campus Iguatu, Laboratório de Solos, Água e Tecidos Vegetais. End: Rod. Iguatu - Várzea Alegre, km 05, Vila Cajazeiras, CEP 63500-000, Fone: (88) 3582-1000, ramal 245. Email: andreiaafb@gmail.com; gemanogomes@ifce.edu.br; adrianoerique@ifce.edu.br; cleene03@hotmail.com 2 IFCE Campus Iguatu, D epto. de Tecnologia em Irrigação e Drenagem. Fone: (88) 3582-1000, Ramal 245. Email: helbaaraujo23@yahoo.com.br
} 


\section{INTRODUÇÃO}

O semiárido do Brasil, que ocupa uma superfície equivalente a $69,2 \%$ da região Nordeste, sempre apresentou problemas socioeconômicos influenciados muito mais pela má distribuição temporal e espacial das precipitações do que pela insuficiência global deste recurso (Ministério da Integração Nacional, 2005). Para aumentar as limitações da região, $85 \%$ da área se encontra sobre rochas cristalinas impermeáveis, onde a água subterrânea de má qualidade se acha nas fraturas das rochas. Associado à escassez de água, ocorre o problema da falta de garantia de oferta hídrica, uma vez que no semiárido ocorrem os fenômenos das secas e, em sua grande maioria, os rios não são perenes (Palácio et al., 2009).

A agricultura irrigada depende tanto da quantidade como da qualidade da água, sendo a longo prazo a qualidade um dos fatores mais importantes e, de acordo com Ayers \& Westcot (1999), as águas salinas utilizadas na irrigação podem representar risco para produção agrícola das culturas. Os efeitos da salinidade nas plantas são devidos à salinidade ou à sodicidade mas, usualmente, ambos estão envolvidos. A salinidade diminui o potencial externo de água reduzindo a disponibilidade de água às culturas, que podem reduzir a produção em até $50 \%$ (Santana et al., 2007).

Altos níveis de sais nas águas de irrigação, tanto são prejudiciais ao desenvolvimento das culturas como causam a obstrução dos sistemas de irrigação (Garcia et al., 2008). A qualidade da água para fins agrícolas obedece a uma classificação, determinada pela concentração de alguns íons, tais como o sódio, potássio, cloretos e os sulfatos, além de outros parâmetros, como sólidos dissolvidos e a condutividade elétrica.

Os sais são transportados pelas águas de irrigação e depositados no solo, onde se acumulam sempre que a água se evapora ou é consumida pelas culturas. Os sais do solo e da água reduzem a disponibilidade da água para as plantas a tal ponto que afetam os rendimentos das culturas (Ayers \& Westcot, 1999).

Algumas culturas produzem rendimentos aceitáveis a níveis altos de salinidade e outras são sensíveis a níveis relativamente baixos. Esta diferença se deve à melhor capacidade de adaptação osmótica que algumas culturas têm, o que permite absorver, mesmo em condições de salinidade, maior quantidade de água (Ayers \& Westcot, 1999), pois a importância da utilização da água para irrigação leva em conta, além da composição físicoquímica da água, as características da espécie vegetal (tolerância à salinidade, seu ciclo de vida, etc.) e do solo (permeabilidade, porosidade, textura, composição mineral, etc.).

A condutividade elétrica da água é o parâmetro mais empregado para avaliar a salinidade da água, a qual corresponde à medida da capacidade dos íons presentes na água em conduzir eletricidade e cresce proporcionalmente ao aumento da concentração dos sais (Ribeiro et al., 2005). Entretanto, quatro aspectos importantes devem ser considerados salinidade, sodicidade, toxicidade de íons e teores de bicarbonato. Essas variáveis são fundamentais na determinação da qualidade agronômica da água. Palácio et al., (2009), estudando a dinâmica dos sais das águas superficiais e subterrâneas para fins de irrigação do rio Trussu, município de Iguatu, CE observaram que as águas foram de qualidade adequada para a agricultura irrigada, sem riscos para as culturas quando se trata de fontes hídricas superficiais; já com relação às fontes subterrâneas em dois pontos amostrados, a qualidade da água apresentou forte risco de restrição quanto ao seu uso na agricultura.

No estado do Ceará a qualidade das águas superficiais que são responsáveis pela recarga dos poços dos aluviões e que também são as principais fontes para irrigação, apresenta variação sazonal dos sais (Meireles et al., 2007; Andrade et al., 2005). Estudos em diferentes regiões do estado têm classificado as águas para irrigação em diferentes classes, com relação ao diagrama de Piper. A bacia hidrográfica do Acaraú tem águas com predomínio da classe sódica (Lobato et al., 2008). Já na bacia do Curu, no período seco o predomínio é de águas mistas, quanto aos cátions, e cloretadas, quanto aos ânions (Frota Júnior, 2006).

Barroso et al., (2010), estudando as águas subterrâneas da região do Baixo Jaguaribe observaram, segundo o diagrama de Piper, que as águas tiveram classificação geral em 47,5\%, enquadrando-se na classe de águas bicarbonatadas sódicas e 40,0\% como águas cloretadas sódicas; apesar disto o sódio prevaleceu sobre os demais cátions e os bicarbonatos sobre os demais ânions.

São necessários, contudo, estudos regionais nas diversas situações de cultivo, avaliando-se as respostas das culturas à salinidade da água em diferentes tipos de solo. Propõe-se, então, com este trabalho, avaliar a qualidade das águas superficiais e subterrâneas para fins de irrigação utilizadas em áreas efetivamente importantes para o desenvolvimento da agricultura irrigada na região centro sul do estado do Ceará.

\section{Material E MÉTODOS}

O estudo foi realizado em áreas pertencentes aos municípios de Cariús, Jucás e Quixelô, situados na região Centro Sul do estado do Ceará. A área em estudo está inserida em uma região de clima classificado, de acordo com KÖPPEN, como BSw'h', ou seja, semiárido quente e seco, com chuvas concentradas no outono/inverno, com temperatura média mensal sempre superior a $18{ }^{\circ} \mathrm{C}$.

De acordo com o Mapa de Solos do Estado do Ceará (IPLANCE, 1997), ocorrem predominantemente três tipos de solo nos municípios em estudo: Argilossolo (solos com horizonte B textural, não hidromóficos, com argila de atividade baixa e, em geral, fortemente ácida e de baixa fertilidade natural, apresentando drenagem moderada e/ou imperfeita, derivados de sedimentos argilo-arenosos do Terceário); Neossolos Flúvicos (pouco desenvolvidos, provenientes de deposição fluvial recente, alta fertilidade e de grande potencial agrícola, que ocorrem nas várzeas dos cursos d'água, constituído por sedimentos fluviais não consolidados de natureza e granulometria variadas); Neossolo Litólico (pouco desenvolvidos, rasos a muito rasos, possuindo um horizonte "A" firmado diretamente sobre a rocha, drenagem variando de moderada a acentuada e, comumente, são bastante susceptíveis à erosão, em decorrência de sua reduzida espessura horizonte 
A fraco, textura variando de arenosa, média a argilosa, com substrato composto por arenito, argilito, síltito, folhelhos, calcário e conglomerados - Grupo Jaibaras).

Foram coletadas, mensalmente, amostras de águas superficiais provenientes do Rio Jaguaribe e fontes subterrâneas provenientes de poços, durante o período abril a junho de 2010. Os pontos de amostragem foram distribuídos da seguinte forma, nos referidos municípios: Jucás (12 pontos), Cariús (01 ponto) e Quixelô (10) pontos.

As amostras de água foram coletadas em tubos plásticos com volume de $2.000 \mathrm{~mL}$ os quais foram previamente lavados com água destilada e secados. Antes da coleta propriamente dita, fez-se a tríplice lavagem dos recipientes com a água da fonte de coleta. No ato da coleta cada amostra recebeu um número de identificação e, posteriormente, foram mantidas refrigeradas ou acondicionadas em depósito com gelo, até serem levadas ao laboratório. As análises efetuadas seguiram a metodologia proposta pelo Standard Methods (APHA, 1998) e foram realizadas no Laboratório de Solos, Água e Tecidos Vegetais do Instituto Federal de Educação, Ciência e Tecnologia do Ceará - IFCE Campus Iguatu Unidade II.

Foram analisados os seguintes parâmetros: cálcio - $\mathrm{Ca}^{++}$ $\left(\mathrm{mmol}_{\mathrm{c}} \mathrm{L}^{-1}\right)$, magnésio $-\mathrm{Mg}^{++}\left(\mathrm{mmol}_{\mathrm{c}} \mathrm{L}^{-1}\right)$, sódio $-\mathrm{Na}^{+}\left(\mathrm{mmol}_{\mathrm{c}}\right.$ $\left.\mathrm{L}^{-1}\right)$, potássio $-\mathrm{K}^{+}\left(\mathrm{mmol}_{\mathrm{c}} \mathrm{L}^{-1}\right)$, cloreto $-\mathrm{Cl}^{-} \quad\left(\mathrm{mmol}_{\mathrm{c}} \mathrm{L}^{-1}\right)$, carbonato $-\mathrm{CO}_{3}{ }^{2-}\left(\mathrm{mmol}_{\mathrm{c}} \mathrm{L}^{-1}\right)$, bicarbonato $-\mathrm{HCO}_{3}{ }^{-}\left(\mathrm{mmol}_{\mathrm{c}} \mathrm{L}^{-1}\right)$, sulfato $-\mathrm{SO}_{4}^{2-}\left(\mathrm{mmol}_{\mathrm{c}} \mathrm{L}^{-1}\right)$, condutividade elétrica $-\mathrm{CE}\left(\mathrm{dS} \mathrm{m}^{-1}\right)$ e a relação de adsorção de sódio (RAS). As determinações de cálcio + magnésio $\left(\mathrm{Ca}^{2+}+\mathrm{Mg}^{2+}\right)$ e de cloreto $\left(\mathrm{Cl}^{-}\right)$foram obtidas por titulação com a solução padrão de EDTA a 0,01M e solução padrão de Nitrato de Prata $\left(\mathrm{AgNO}_{3}\right)$ a $0,0141 \mathrm{~N}$, respectivamente. $\mathrm{O}$ sulfato $\left(\mathrm{SO}_{4}^{2-}\right)$ foi determinado espectrofotometricamente, $\mathrm{o}$ sódio $\left(\mathrm{Na}^{+}\right)$e potássio $\left(\mathrm{K}^{+}\right)$solúveis foram determinados no fotômetro de emissão de chama. O bicarbonato $\left(\mathrm{HCO}_{3}^{-}\right)$e carbonato $\left(\mathrm{CO}_{3}^{2-}\right)$ foram obtidos por titulação com solução padrão de ácido sulfúrico $\left(\mathrm{H}_{2} \mathrm{SO}_{4}\right)$ a $0,02 \mathrm{~N}$ e a condutividade elétrica (CE) foi obtida com um condutivímetro de bancada.

De posse dos resultados das análises, os mesmos foram inseridos através do software Qualigraf pelo diagrama de Piper, a fim de classificar e comparar os distintos grupos de águas quanto aos cátions e ânions dominantes.

\section{Resultados E DisCussão}

Os parâmetros analisados nas fontes hídricas superficiais estão inseridos nas Tabelas 1 e 2 . A partir dos resultados obtidos pode-se observar grande variabilidade nos parâmetros analisados, refletida pelos indicadores apresentados na Tabela 1, quando se trata de águas superficiais e na Tabela 2 se observa somente dados realizados em um único ponto (8-Cariús).

Avaliando a Tabela 1 quanto à variabilidade de cada parâmetro, observa-se que as concentrações do íon sódio para as águas superficiais no município de Jucás variaram de 0,62 mmol $_{c} \mathrm{~L}^{-1}$ a 2,46 $\mathrm{mmol}_{\mathrm{c}} \mathrm{L}^{-1}$. Todos os pontos estudados apresentaram valores dentro do limite ideal para o uso na irrigação $\left(<3,00 \mathrm{mmol}_{\mathrm{c}} \mathrm{L}^{-1}\right)$, conforme estabelecido pela University of California Committee of Consultans (Ayers \& Westcot, 1999).

Esses resultados são semelhantes aos observados por Arraes et al. (2009), estudando as águas da bacia do Curu. Os valores abaixo do limite $\left(<3,00 \mathrm{mmol}_{\mathrm{c}} \mathrm{L}^{-1}\right)$, corroboram com os observados por Arraes et al. (2009), quando obtiveram baixas concentrações desse íon na bacia do Curu, justificando o fato como consequência dos pontos amostrados estarem localizados à jusante da barragem, havendo um fluxo de água que proporciona diluições.

Entretanto, de acordo com a Tabela 2, no município de Cariús foi observada uma concentração do íon sódio, superior ao

Tabela 1. Resultado das análises, média, desvio padrão, valor máximo e mínimo das águas superficiais para irrigação, município de Jucás na região Centro Sul, no estado do Ceará, 2010

\begin{tabular}{|c|c|c|c|c|c|c|c|c|c|}
\hline \multirow{3}{*}{ Pontos } & \multicolumn{9}{|c|}{ Parâmetros } \\
\hline & $\mathrm{Na}^{+}$ & $\mathrm{K}^{+}$ & $\mathrm{Ca}^{2+}+\mathrm{Mg}^{2+}$ & $\mathrm{Cl}^{-}$ & $\mathrm{HCO}_{3}{ }^{-}$ & $\mathrm{CO}_{3}{ }^{2 \cdot}$ & $\mathrm{SO}_{4}{ }^{2-}$ & \multirow{2}{*}{$\begin{array}{c}\text { CE } \\
\mathrm{dS} \mathrm{m}^{-1}\end{array}$} & \multirow{2}{*}{$\begin{array}{c}\text { RAS } \\
\left(\mathrm{mmol} \mathrm{L}^{-1}\right)^{0,5}\end{array}$} \\
\hline & \multicolumn{7}{|c|}{$\mathrm{mmol}_{\mathrm{c}} \mathrm{L}^{-1}$} & & \\
\hline 1- Jucás & 2,46 & 0,16 & 2,18 & 1,71 & 1,12 & 0,00 & 0,11 & 0,57 & 2,36 \\
\hline 2-J ucás & 2,26 & 0,16 & 1,92 & 1,71 & 1,02 & 0,00 & 0,10 & 0,45 & 2,31 \\
\hline 3-jucás & 2,26 & 0,12 & 1,88 & 1,45 & 1,04 & 0,00 & 0,10 & 0,40 & 2,33 \\
\hline 4-J ucás & 2,26 & 0,10 & 1,80 & 1,45 & 0,90 & 0,08 & 0,09 & 0,37 & 2,38 \\
\hline 5-Jucás & 2,46 & 0,16 & 2,11 & 1,83 & 1,08 & 0,00 & 0,07 & 0,47 & 2,40 \\
\hline 6-J ucás & 0,62 & 0,08 & 0,85 & 0,49 & 0,44 & 0,00 & 0,08 & 0,15 & 0,95 \\
\hline 7-J ucás & 2,06 & 0,10 & 2,53 & 1,42 & 1,04 & 0,00 & 0,23 & 0,33 & 1,83 \\
\hline Média & 2,05 & 0,13 & 1,90 & 1,44 & 0,95 & 0,01 & 0,11 & 0,39 & 2,08 \\
\hline Desvio Padrão & 0,65 & 0,03 & 0,52 & 0,45 & 0,23 & 0,03 & 0,05 & 0,13 & 0,54 \\
\hline Máximo & 2,46 & 0,16 & 2,53 & 1,83 & 1,12 & 0,08 & 0,23 & 0,57 & 2,40 \\
\hline Mínimo & 0,62 & 0,08 & 0,85 & 0,49 & 0,44 & 0,00 & 0,07 & 0,15 & 0,95 \\
\hline
\end{tabular}

Tabela 2. Resultado das análises de águas superficiais para irrigação, município de Cariús na região Centro Sul, no estado do Ceará, 2010

\begin{tabular}{|c|c|c|c|c|c|c|c|c|c|}
\hline \multirow{3}{*}{ Pontos } & \multicolumn{9}{|c|}{ Parâmetros } \\
\hline & $\mathrm{Na}^{+}$ & $\mathbf{K}^{+}$ & $\mathrm{Ca}^{2+}+\mathrm{Mg}^{2+}$ & $\mathrm{Cl}^{-}$ & $\mathrm{HCO}_{3}{ }^{\circ}$ & $\mathrm{CO}_{3}{ }^{2-}$ & $\mathrm{SO}_{4}{ }^{2-}$ & \multirow{2}{*}{$\begin{array}{c}\text { CE } \\
\text { dS } \mathrm{m}^{-1}\end{array}$} & \multirow{2}{*}{$\begin{array}{c}\text { RAS } \\
\left(\mathrm{mmol} \mathrm{L}^{-1}\right)^{0}\end{array}$} \\
\hline & \multicolumn{7}{|c|}{$\mathrm{mmol}_{\mathrm{c}} \mathrm{L}^{-1}$} & & \\
\hline 8-Cariús & 4,12 & 0,12 & 3,14 & 2,90 & 1,82 & 0,04 & 0,21 & 0,70 & 3,29 \\
\hline
\end{tabular}


limite de tolerância das plantas mais sensíveis a esse íon; o mesmo foi encontrado em um único ponto em estudo, que foi de 4,12 mmol $_{c} \mathrm{~L}^{-1}$. Possivelmente esta elevação deve ser em decorrência do retorno da água utilizada nas áreas irrigadas ao longo do seu percurso; já os valores de $\mathrm{Ca}^{2+}+\mathrm{Mg}^{2+}$ para as Tabelas 1 e 2, se encontram abaixo do limite $\left(<5 \mathrm{mmol}_{\mathrm{c}} \mathrm{L}^{-1}\right)$ proposto por Ayers \& Westcot (1999), não apresentando risco algum quando aplicadas às culturas.

As concentrações de cloreto nas águas superficiais em todos os pontos estudados (Tabelas 1 e 2), não apresentam restrições ao serem aplicadas nas culturas, de acordo com Ayers \& Westcot (1999). Para as águas no município de Jucás (Tabela 1) nota-se, quanto ao bicarbonato, que elas se enquadram na classe de nenhuma restrição; já no ponto estudado 8-Cariús (Tabela 2), obtiveram valor de $1,82 \mathrm{mmol}_{\mathrm{c}} \mathrm{L}^{-1}$ enquadrando-se na classe de restrição moderada (Ayers \& Westcot, 1999).

Verifica-se ainda que os valores de CE para as águas superficiais nos pontos estudados no município de Jucás (Tabela 1), não atingiram o limite de $0,7 \mathrm{dS} \mathrm{m}^{-1}$ proposto por Ayers \& Westcot (1999). Desta forma, essas águas podem ser classificadas sem nenhuma restrição quanto ao uso na irrigação, cujos resultados corroboram com os de Frota Júnior (2006), que encontrou valores de CE sem restrição para irrigação na bacia do Curu-Ceará, enquanto no município de Cariús, no ponto 8-Cariús (Tabela 2), este valor foi de $0,70 \mathrm{dS} \mathrm{m}^{-1}$, enquadrando-se na classe de restrição moderada, que é de 0,7 $-0,3 \mathrm{dS} \mathrm{m}^{-1}$.

A variação da RAS para as fontes hídricas superficiais em estudo nos municípios de Jucás e Cariús pode ser vista nas Tabelas 1 e 2, respectivamente.

Para o município de Jucás (Tabela 1), o valor médio de RAS observado foi 2,08 e a CE $\left(0,39 \mathrm{dS} \mathrm{m}^{-1}\right)$, que segundo Richards (1954), a água é classificada em $\mathrm{C}_{2} \mathrm{~S}_{1}$, a qual representa perigo de salinidade de médio e baixo risco de sodicidade; já no município de Cariús, no ponto 8-Cariús (Tabela 2 ) o valor médio da RAS foi 3,29 e a CE $0,70 \mathrm{dS} \mathrm{m}^{-1}$ classificando a água em $\mathrm{C}_{3} \mathrm{~S}_{1}$; de acordo com Richards (1954), a água apresenta alto risco de salinidade e baixo risco de sodicidade. Palácio et al., (2009), estudando a dinâmica dos sais das águas superficiais para irrigação do rio Trussu (Iguatu, CE) observaram que as águas foram de qualidade adequada para a agricultura irrigada, sem riscos para as culturas; já Andrade et. al., (2006) estudando a qualidade das águas na bacia do Acaraú, Ceará, observaram que em sua totalidade as águas apresentaram riscos altos e moderados/altos de problemas com a infiltração provocados pela sodicidade das águas e as áreas de maiores risoc estão localizadas em áreas onde as águas apresentam valores de CE $<0,21 \mathrm{dS} \mathrm{m}^{-1}$.

Os parâmetros analisados nas fontes hídricas subterrâneas estão inseridos nas Tabelas 3 e 4.

Tabela 3. Resultado das análises, média, desvio padrão, valor máximo e mínimo das águas subterrâneas para irrigação, município de Jucás na região Centro Sul, no estado do Ceará, 2010

\begin{tabular}{|c|c|c|c|c|c|c|c|c|c|}
\hline \multirow{3}{*}{ Pontos } & \multicolumn{9}{|c|}{ Parâmetros } \\
\hline & $\mathrm{Na}^{+}$ & $\mathbf{K}^{+}$ & $\mathrm{Ca}^{2+}+\mathrm{Mg}^{2+}$ & $\mathrm{Cl}^{-}$ & $\mathrm{HCO}_{3}{ }^{-}$ & $\mathrm{CO}_{3}{ }^{2-}$ & $\mathrm{SO}_{4}{ }^{2-}$ & \multirow{2}{*}{$\begin{array}{c}\text { CE } \\
d S \mathrm{~m}^{-1}\end{array}$} & \multirow{2}{*}{$\begin{array}{c}\text { RAS } \\
\left(\mathrm{mmol} \mathrm{L}^{-1}\right)^{0,5}\end{array}$} \\
\hline & \multicolumn{7}{|c|}{$\mathrm{mmol}_{\mathrm{c}} \mathrm{L}^{-1}$} & & \\
\hline 9-Jucás & 2,26 & 0,16 & 1,95 & 1,80 & 1,00 & 0,00 & 0,08 & 0,45 & 2,29 \\
\hline 10-J ucás & 0,62 & 0,08 & 0,96 & 0,46 & 0,46 & 0,00 & 0,09 & 0,15 & 0,89 \\
\hline 11-J ucás & 10,25 & 0,23 & 5,45 & 1,48 & 5,66 & 0,00 & 0,13 & 0,63 & 6,21 \\
\hline 12-J ucás & 8,77 & 0,13 & 4,90 & 1,94 & 4,60 & 0,00 & 0,06 & 0,74 & 5,60 \\
\hline 13-J ucás & 5,22 & 0,08 & 3,45 & 1,51 & 4,32 & 0,00 & 0,17 & 0,92 & 3,97 \\
\hline Média & 5,42 & 0,14 & 3,34 & 1,44 & 3,21 & 0,00 & 0,11 & 0,58 & 3,79 \\
\hline Desvio Padrão & 4,11 & 0,06 & 1,90 & 0,58 & 2,32 & 0,00 & 0,04 & 0,29 & 2,23 \\
\hline Máximo & 10,25 & 0,23 & 5,45 & 1,94 & 5,66 & 0,00 & 0,17 & 0,92 & 6,21 \\
\hline Mínimo & 0,62 & 0,08 & 0,96 & 0,46 & 0,46 & 0,00 & 0,06 & 0,15 & 0,89 \\
\hline
\end{tabular}

Tabela 4. Resultado das análises, média, desvio padrão, valor máximo e mínimo das águas subterrâneas para irrigação, município de Q uixelô na região Centro Sul, no estado do Ceará, 2010

\begin{tabular}{|c|c|c|c|c|c|c|c|c|c|}
\hline \multirow{3}{*}{ Pontos } & \multicolumn{9}{|c|}{ Parâmetros } \\
\hline & $\mathrm{Na}^{+}$ & $\mathbf{K}^{+}$ & $\mathrm{Ca}^{2+}+\mathrm{Mg}^{2+}$ & $\mathrm{Cl}^{-}$ & $\mathrm{HCO}_{3}^{\circ}$ & $\mathrm{CO}_{3}{ }^{2-}$ & $\mathrm{SO}_{4}{ }^{2-}$ & \multirow{2}{*}{$\begin{array}{c}\text { CE } \\
\mathrm{dS} \mathrm{m}^{-1}\end{array}$} & \multirow{2}{*}{$\begin{array}{c}\text { RAS } \\
\left(\mathrm{mmol} \mathrm{L}^{-1}\right)^{0,5}\end{array}$} \\
\hline & \multicolumn{7}{|c|}{$\mathrm{mmol}_{\mathrm{c}} \mathrm{L}^{-1}$} & & \\
\hline 14-Quixelô & 23,59 & 0,25 & 3,03 & 9,57 & 1,02 & 0,00 & 0,25 & 1,60 & 19,17 \\
\hline 15-Quixelô & 14,68 & 0,28 & 1,96 & 5,28 & 1,02 & 0,00 & 0,13 & 0,89 & 14,83 \\
\hline 16-Quixelô & 19,14 & 0,25 & 2,53 & 7,22 & $\begin{array}{l}1,0< \\
1,44\end{array}$ & 0,00 & 0,16 & 1,21 & 17,02 \\
\hline 17-Quixelô & 19,14 & 0,43 & 2,87 & 7,69 & $\begin{array}{l}1,44 \\
1,40\end{array}$ & 0,00 & 0,16 & $\begin{array}{l}1,21 \\
1,18\end{array}$ & $\begin{array}{l}15,98 \\
15,98\end{array}$ \\
\hline 18-Quixelô & 17,65 & 1,24 & 1,65 & 5,89 & $\begin{array}{l}1,00 \\
1,02\end{array}$ & 0,00 & 0,25 & $\begin{array}{l}1,10 \\
1,00\end{array}$ & 19,43 \\
\hline 19-Quixelô & 17,65 & 0,25 & 2,34 & 6,62 & $\begin{array}{l}1,02 \\
1,06\end{array}$ & 0,00 & 0,21 & $\begin{array}{l}1,11 \\
1,11\end{array}$ & 16,32 \\
\hline 20-Quixelô & 8,74 & 0,36 & 1,49 & 0,84 & 0,62 & 0,00 & 0,03 & 0,30 & 10,13 \\
\hline 21-Quixelô & 10,23 & 0,19 & 1,15 & 3,10 & 0,76 & 0,00 & 0,19 & 0,59 & 13,49 \\
\hline 22-Quixelô & 11,71 & 0,63 & 2,26 & 4,12 & 1,02 & 0,00 & 0,16 & 0,83 & 11,02 \\
\hline 23-Quixelô & 23,59 & 0,19 & 2,11 & 4,90 & 1,32 & 0,00 & 0,21 & 1,38 & 22,96 \\
\hline Média & 15,84 & 0,41 & 2,14 & 5,52 & 1,07 & 0,00 & 0,18 & 1,01 & 16,03 \\
\hline Desvio Padrão & 4,86 & 0,32 & 0,60 & 2,48 & 0,26 & 0,00 & 0,06 & 0,38 & 3,92 \\
\hline Máximo & 23,59 & 1,24 & 3,03 & 9,57 & 1,44 & 0,00 & 0,25 & 1,60 & 22,96 \\
\hline Mínimo & 8,74 & 0,19 & 1,15 & 0,84 & 0,62 & 0,00 & 0,03 & 0,30 & 10,13 \\
\hline
\end{tabular}


Os parâmetros analisados nas fontes hídricas subterrâneas nos municípios de Jucás e Quixelô, estão inseridos nas Tabelas 3 e 4 , respectivamente.

Com relação ao teor de sódio em Jucás (Tabela 3), ocorreu uma variação de 0,62 a $10,25 \mathrm{mmol}_{\mathrm{c}} \mathrm{L}^{-1}$; entretanto, o valor

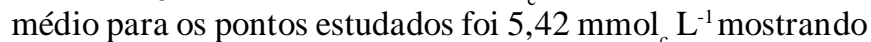
que as águas subterrâneas, apresentaram concentrações que ultrapassaram os limites de tolerância para as culturas mais sensíveis $\left(<3,00 \mathrm{mmol}_{\mathrm{c}} \mathrm{L}^{-1}\right)$ estabelecidos por Ayers \& Westcot (1999), tornando-as impróprias para uso na irrigação; já no município de Quixelô (Tabela 4), esses valores variaram de 8,74 a 23,59 mmol $\mathrm{L}^{-1}$; entretanto, o valor médio para os pontos estudados foi $15,84 \mathrm{mmol}_{\mathrm{c}} \mathrm{L}^{-1}$ mostrando que as águas possuem grau de restrição severo $\left(>9,00 \mathrm{mmol}_{\mathrm{c}} \mathrm{L}^{-1}\right)$, para uso na irrigação.

Os valores de $\mathrm{Ca}^{2+}+\mathrm{Mg}^{2+}$ nos municípios de Jucás e Quixelô (Tabelas 3 e 4), se encontram, respectivamente abaixo do limite ( $<5 \mathrm{mmol}_{\mathrm{c}} \mathrm{L}^{-1}$ ) proposto por Ayers \& Westcot (1999), não apresentando qualquer risco, quando aplicados às culturas, com exceção do ponto 11-Jucás, que apresenta risco moderado para as culturas.

Para o teor de cloreto no município de Jucás (Tabela 3), todos os pontos estudados estão dentro dos limites permitidos pelos referidos autores, de $3 \mathrm{mmol}_{\mathrm{c}} \mathrm{L}^{-1}$; essas águas, quando aplicadas às culturas, não afetam seu rendimento.

Já para estudos realizados no município de Quixelô (Tabela 4), com exceção do ponto 20-Quixelô $\left(0,84 \mathrm{mmol}_{\mathrm{c}} \mathrm{L}^{-1}\right)$, os demais ultrapassaram os limites permitidos pelos referidos autores, de $3 \mathrm{mmol}_{\mathrm{c}} \mathrm{L}^{-1}$; essas concentrações variaram de 3,10 a 9,57 mmol $\mathrm{L}^{-1}$; essas águas, se aplicadas às culturas sensíveis, afetarão seu rendimento; entretanto, para as culturas mais resistentes, quando irrigadas por superfície os limites com relação ao grau de restrição são de $3-9 \mathrm{mmol}_{\mathrm{c}} \mathrm{L}^{-1}$ ligeira e moderada e $>9,00$ mmol $\mathrm{L}^{-1}$ severa.

Em relação aos valores de bicarbonato nota-se que as águas subterrâneas no município de Jucás (Tabela 3), obtiveram valor médio de 3,21 mmol $\mathrm{L}^{-1}$, haja vista que essas águas se enquadram na classe de restrição para uso de ligeira a moderada, segundo Ayers \& Westcot (1999) que é de 1,5 - 8,5 $\mathrm{mmol}_{\mathrm{c}} \mathrm{L}^{-1}$. Já no município de Quixelô (Tabela 4), o valor médio encontrado foi $1,07 \mathrm{mmol}_{\mathrm{c}} \mathrm{L}^{-1}$, se enquadrando na classe de nenhuma restrição quanto ao uso na irrigação.

Com relação à CE, para as fontes subterrâneas (Tabelas $3 \mathrm{e}$ 4) apresentam restrição quanto ao uso para a irrigação somente no município de Quixelô (Tabela 4) onde o valor médio obtido foi $1,01 \mathrm{dS} \mathrm{m}^{-1}$, desta forma, essas águas enquadram-se na classe de restrição moderada, que é de $0,7-0,3 \mathrm{dS} \mathrm{m}{ }^{-1}$; já no município de Jucás (Tabela 3) o valor médio de CE foi 0,58 dS $\mathrm{m}^{-1}$, essas águas podem ser classificadas sem nenhuma restrição quanto ao uso na irrigação.

Com relação à RAS para as fontes hídricas subterrâneas no município de Jucás (Tabela 3 ) o valor médio de RAS observado foi 3,79; com o valor médio da $\mathrm{CE}\left(0,58 \mathrm{dS} \mathrm{m}^{-1}\right)$ a classificação da água foi $\mathrm{C}_{2} \mathrm{~S}_{1}$, representando perigo de salinidade de médio e baixo risco de sodicidade, segundo Richards (1954).

Já no município de Quixelô o valor médio de RAS foi 16,03 e o da CE 1,01 dS m¹ (Tabela 4). De acordo com Richards (1954), a classificação da água foi $\mathrm{C}_{3} \mathrm{~S}_{3}$; esta classificação representa perigo de salinidade e sodicidade alto em que, uma vez usada nas culturas, afetará o rendimento das mesmas ocasionando problemas de infiltração da água no solo.

Palácio et al., (2009), estudando a dinâmica dos sais das águas subterrâneas para irrigação do rio Trussu, município de Iguatu, CE, observaram que as águas em dois pontos estudados possuem grande restrição de uso na irrigação.

Entretanto, de posse dos resultados apresentados nas Tabelas 1, 2, 3 e 4, obtiveram-se os resultados do diagrama de Piper para as águas da região Centro Sul do estado do Ceará (Figura 1).

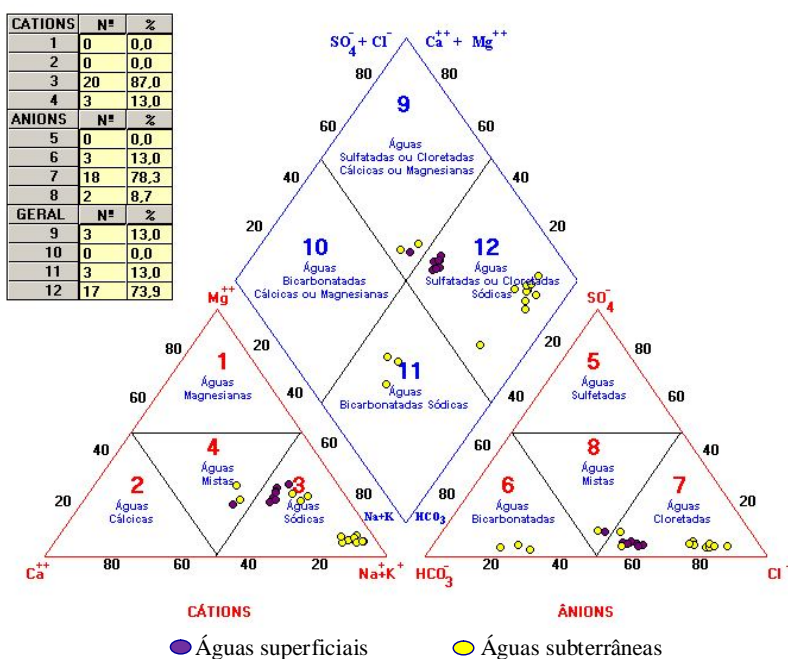

Figura 1. D iagrama de Piper para a classificação das águas superficiais e subterrâneas da região Centro Sul, no estado do Ceará, 2010

Quanto aos cátions, a maior parte das amostras $(87,0 \%)$ se enquadra na classe de águas sódicas, enquanto 13,0\% foram classificados como mistas. Resultados semelhantes foram obtidos por Lobato et al. (2008), estudando a sazonalidade na qualidade da água de irrigação do Distrito Irrigado Baixo Acaraú, Ceará, verificando predomínio da classe sódica nos períodos chuvoso e seco; já Frota Júnior (2006), encontrou predomínio de águas mistas quanto aos cátions na bacia do Curu, Ceará.

Com relação aos ânions, verifica-se que 78,3\% das águas se apresentam como cloretadas, $13,0 \%$ bicarbonatadas e apenas $8,70 \%$ correspondendo a duas amostras, como mistas. Ainda na Figura 1 se nota, que a classe predominante é a cloretada, sendo as demais bicarbonatadas (3 amostras) e mistas (2 amostras) correspondendo a 13 e $8,7 \%$, respectivamente, das amostras. Resultados semelhantes encontrou Frota Júnior (2006), ao verificar a presença de águas cloretadas no período seco, na bacia do Curu, Ceará. De acordo com a classificação geral, 73,9\% das águas se encontram na classe sulfatada ou cloretada sódica, em que o sódio prevaleceu sobre os demais cátions e o cloreto sobre os demais ânions; contudo, de modo geral, as águas subterrâneas possuem mais restrições quando aplicadas às culturas que as superficiais, devido a concentração de sais ser mais elevada.

Pereira et al., (2006) estudando a qualidade das águas superficiais na bacia da Gameleira, município de Aiuaba, Ceará; observaram que segundo o diagrama de Piper, a maioria das águas tiveram classificação do tipo bicarbonatada mista, 
indicando a presença de águas novas provenientes de chuvas; já Barroso et al., (2010), estudando as águas subterrâneas da região do Baixo Jaguaribe, Ceará, observaram, segundo o diagrama de Piper, que as águas tiveram classificação geral em $47,5 \%$ das mesmas e se encontram na classe de águas bicarbonatadas sódicas e 40,0\% como águas cloretadas sódicas; e entretanto, o sódio prevaleceu sobre os demais cátions e os bicarbonatos sobre os demais ânions.

\section{CONClusÕES}

1. Conclui-se, portanto, que as águas da região Centro Sul do estado do Ceará foram classificadas em $\mathrm{C}_{2} \mathrm{~S}_{1}$ e $\mathrm{C}_{3} \mathrm{~S}_{1}$ para fontes hídricas superficiais e $\mathrm{C}_{2} \mathrm{~S}_{1}$ e $\mathrm{C}_{3} \mathrm{~S}_{3}$ para as fontes hídricas subterrâneas, as quais apresentam maior risco de salinidade e sodicidade quanto ao uso para irrigação.

2. De acordo com o diagrama de Piper, os resultados mostraram, de modo geral, predominância das águas sódicas com $87,0 \%$ quando se consideram os cátions, e cloretadas com $78,3 \%$ quanto aos ânions, porém, de acordo com a classificação geral, predominaram as águas sulfatadas ou cloretadas sódicas, com $73,9 \%$.

\section{LITERATURA CITADA}

Andrade, E. M.; Batista, T. M.; Teixeira, A. S.; Meireles, M.; Souza, B. F. S. Mapa de vulnerabilidade da bacia do Acaraú, Ceará, à qualidade das águas de irrigação, pelo emprego do GIS. Ciência Agronômica, v.37, p.280-287, 2006.

Andrade, E. M.; Palácio, H. A. Q.; Crisóstomo, L. A.; Souza, I. H.; Teixeira, A. S. Índice de qualidade de água, uma proposta para o vale do rio Trussu, Ceará. Revista Ciência Agronômica, v.36, p.135-142, 2005.

APHA - American Public Health Association. Standard methods for the examination of water and wastewater. 20. ed. Washigton, 1998. 1220p.

Arraes, F. D. D.; Andrade, E. M.; Palácio, H. A. Q.; Sousa, C. H. C.; Silva, J. A.; Frota Júnior, J. I. Identificação dos íons determinantes da condutividade elétrica nas águas superficiais da bacia do Curu, Ceará. Revista Ciências Agronômica, v.40, p.346-355, 2009.

Ayers, R. S.; Westcot, D. W. A qualidade da água na agricultura. 2. ed. Campina Grande: UFPB, 1999, 153p. Estudos de Irrigação e Drenagem 29
Barroso, A. de A. F.; Ness, R. L. L.; Filho, R. R. G.; Silva, F. L. da; Chaves, M. J. L.; Lima, C. A. de. Avaliação qualitativa das águas subterrâneas para irrigação na região do Baixo Jaguaribe - Ceará. Revista Brasileira de Agricultura Irrigada. v.4, p.150-155, 2010.

Frota Júnior, J. I. Variabilidade espacial e temporal da qualidade das águas no trecho perenizado da bacia hidrográfica do Curu, Ceará. Fortaleza: UFC, 2006. 101p. Dissertação Mestrado

Garcia, G. de O; Martins Filho, S.; Reis, E. F. dos; Moraes, W. B.; Nazário, A. de A. Alterações químicas de dois solos irrigados com água salina. Revista Ciência Agronômica, v.39, p.7-18, 2008.

IPLANCE/Instituto de Planejamento do Ceará. Atlas do Ceará. Fortaleza: IPLANCE. 1997. CD-Rom.

Lobato, F. A. O.; Andrade, E. M.; Meireles, A. C. M.; Crisostomo, L. A. Sazonalidade na qualidade da água de irrigação do Distrito Irrigado Baixo Acaraú, Ceará. Revista Ciência Agronômica, v.30, p.167-172, 2008.

Meireles, A. C. M.; Frischkorn, H.; Andrade, E. M. Sazonalidade da qualidade das águas do açude Edson Queiroz, bacia do Acaraú, no semiárido cearense. Revista Ciência Agronômica, v.38, p.25-31, 2007.

Ministério da Integração Nacional. Nova delimitação do semiárido brasileiro. Brasília. 2005. 34p. Disponível em: http:/ /www.integracao.gov.br/desenvolvimentoregional/ publicacoes/delimitacao.asp. 21/09/2010.

Palácio, H. A. de Q.; Neto, J. A. C.; Teixeira, A. dos S.; Andrade, E. M. de. Caracterização da potencialidade de uso das águas subterrâneas no vale do Trussu-CE. Revista Ciência Agronômica, v.35, p.316-324, 2009.

Pereira, L.; Santiago M. M. F.; Frischkorn H.; Araújo, J. C. de; Lima, J. O. G. de. A salinidade das águas superficiais e subterrâneas na bacia da Gameleira, município de Aiuaba, Ceará. Revista Águas Subterrâneas, v.20, p.9-18, 2006.

Ribeiro, G. M.; Maia, C. E.; Medeiros, J. F. Uso da regressão linear para estimativa da relação entre a condutividade elétrica e a composição iônica da água de irrigação. Revista Brasileira de Engenharia Agrícola e Ambiental, v.9, p.15-22, 2005.

Richards, L. A. Diagnóstico e rehabilitación de suelos salinos e sódicos. México: Editorial Limusa, 1954. 172/p.

Santana, M. J.; Carvalho, J. A.; Souza, K. J.; Sousa, A. M. G.; Vasconcelos, C. L.; Andrade, L. A. B. Efeitos da salinidade da água de irrigação na brotação e desenvolvimento inicial da cana-de-açúcar (Saccharum spp) e em solos com diferentes níveis texturais. Revista Ciência Agrotécnica, v.31, p.1470-1476, 2007. 